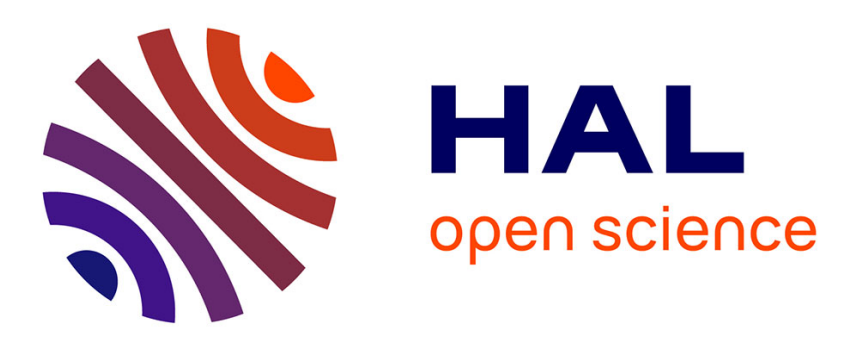

\title{
Democracy and competition: Vertical differentiation and labor in a general equilibrium model
}

\author{
Amani Kahloul, Rim Lahmandi-Ayed, Hejer Lasram, Didier Laussel
}

\section{To cite this version:}

Amani Kahloul, Rim Lahmandi-Ayed, Hejer Lasram, Didier Laussel. Democracy and competition: Vertical differentiation and labor in a general equilibrium model. Journal of Public Economic Theory, 2017, 19 (4), pp.860 - 874. 10.1111/jpet.12256 . hal-01793055

\section{HAL Id: hal-01793055 https://hal-amu.archives-ouvertes.fr/hal-01793055}

Submitted on 7 Feb 2022

HAL is a multi-disciplinary open access archive for the deposit and dissemination of scientific research documents, whether they are published or not. The documents may come from teaching and research institutions in France or abroad, or from public or private research centers.
L'archive ouverte pluridisciplinaire HAL, est destinée au dépôt et à la diffusion de documents scientifiques de niveau recherche, publiés ou non, émanant des établissements d'enseignement et de recherche français ou étrangers, des laboratoires publics ou privés. 


\title{
Democracy and competition: Vertical differentiation and labor in a general equilibrium model
}

\author{
Amani Kahloul ${ }^{1}$ \\ Rim Lahmandi-Ayed ${ }^{2}$ \\ Hejer Lasram ${ }^{3}$ \\ Didier Laussel ${ }^{4}$
}

${ }^{1}$ ISG Sousse-Université de Sousse and UR MASEESSAI, Université de Carthage

${ }^{2}$ ESSAI and UR MASE-ESSAI, Université de Carthage

${ }^{3}$ UR MASE-ESSAI, Université de Carthage; AixMarseille University, CNRS, EHESS, Centrale

Marseille, AMSE

${ }^{4}$ Aix-Marseille University, CNRS, EHESS, Centrale Marseille, AMSE

Amani Kahloul, ISG Sousse-Université de Sousse and UR MASE-ESSAI, Université de Carthage (amani.kahloul@gmail.com).

Rim Lahmandi-Ayed, ESSAI and UR MASE-ESSAI, Université de Carthage

(rim.lahmandi.ayed@gmail.com).

Hejer Lasram, UR MASE-ESSAI, Université de Carthage; Aix-Marseille University, CNRS, EHESS, Centrale Marseille, AMSE (hejer.lasram@gmail.com).

Didier Laussel, Aix-Marseille University, CNRS, EHESS, Centrale Marseille, AMSE (didier.laussel@outlook.fr).
We consider a general equilibrium model with vertical preferences and one or two firms, where workers and consumers are differentiated, respectively, by their sensitivity to effort and their preference for quality. The question in this paper is whether a decentralized choice through majority vote would lead to more or less competition. We compare the duopoly and the monopoly cases from the viewpoint of each individual, then we deduce the choice of the majority. We prove that, under concentrated ownership (where owners have a null density), duopoly is always preferred by the majority; while under egalitarian ownership (where firms are equally shared by all the population), the choice of the majority depends on the relative size of workers' and consumers' segments.

\section{1 | INTRODUCTION}

Collective choice of the best economic policy has always been considered as the responsibility of governments and leaders, what is commonly called "the social planner." What if everybody were given the possibility to express his/her preference? What if the best option were chosen through vote by all individuals, instead of being chosen by a social planner? The choice between several economic options has to be made on the basis of its global effects on the collectivity, taking into account the interdependence between the markets and having in mind that an individual may be affected as a consumer, a worker, a shareholder, and so on.

Accounting for the global effects may be of great importance to deal with the choice concerning more or less competition, education issues, development economics, poverty, and so on. This is in particular the case when the links 
between markets cannot be neglected. With differentiated markets, if we consider that the product's quality results from the worker's effort which in turn affects the worker's utility, the product and the labor markets are interrelated.

In this paper, the question is whether a decentralized collective choice would lead to more or less competition. We determine the collective choice through majority voting between monopoly and duopoly in a general equilibrium setting with vertical preferences, under two extreme ownership structures: egalitarian and concentrated.

The largest part of the literature on vertical differentiation has considered partial equilibrium models with consumers on one side and firms on the other (Amir, Jin, Pech, \& Tröge, 2016; Anderson, de Palma, \& Thisse, 1992; Choi \& Shin, 1992; Li \& Zhang, 2016; Mussa \& Rosen, 1978; Wauthy, 1996). Workers have been integrated in a less abundant literature highlighting the role of skills in the product's quality (Bacchiega, 2007; Gabszewicz \& Turrini, 1999, 2000; Hili, Lahmandi-Ayed, \& Lasram, 2015). But even these papers consider partial equilibrium models with separate categories of agents (firms, workers, and consumers). To our knowledge, only Lutz and Turrini (2006) have considered vertical differentiation within a general equilibrium model. The choice between partial and general equilibrium models may matter importantly regarding how and which economic option a society should choose. In partial equilibrium models, the best option is considered to be the one maximizing the social welfare given by the sum of firms', consumers', and workers' surpluses. In a general equilibrium model, summing utilities has no meaning. Indeed, each agent is potentially a worker, a consumer, and a shareholder in firms. What matters for one individual is the indirect utility at equilibrium resulting from the maximization of his/her utility given his/her income. The aggregation of individual preferences may occur through several mechanisms, among which we choose majority voting.

More precisely, we consider an economy with firms producing a vertically differentiated product using labor and a numéraire as inputs and a population of workers/consumers/shareholders characterized by their preferences for the product quality and by their sensitivity to effort. Each individual decides to work or not and in which firm and decides to purchase one unit of the differentiated product or not and from which firm, in order to maximize his/her utility given his/her income. Firms set their qualities and prices within a noncooperative game, anticipating market clearing wages. We compare the monopoly and the duopoly cases from the viewpoint of each individual, thus deducing the preference of the majority. ${ }^{1}$ We deal with this issue in two cases. In the first, the ownership is concentrated, i.e., the proportion of individuals who are shareholders is negligible. In the second, the ownership is egalitarian, i.e., firms are equally shared by individuals.

Since each individual is at the same time a consumer, a worker, and a shareholder, we distinguish three effects which influence his/her choice between duopoly and monopoly. For a worker/consumer, duopoly is better than monopoly because competition lowers prices and raises wages. For a shareholder, monopoly is better since monopoly's profits are greater than the joint duopoly profit.

Under concentrated ownership, because there is no shareholder effect, the worker/consumer effects dominate. Indeed, everybody prefers duopoly to monopoly or is indifferent between both. Thus, the majority votes for duopoly. However, under egalitarian ownership, we show that the preference of the majority depends on the relative extent of the consumers' and workers' segments. Indeed, when the consumers' segment is large relative to the workers' one, duopoly is preferred by the majority. In this case, the consumer/worker effects dominate the shareholder one.

\subsection{Related literature}

Gabszewicz and Vial (1972) pioneered the analysis of general equilibrium under product market imperfections by introducing the Cournot-Walras equilibrium. They suppose that firms, which are in a limited number, act strategically, while consumers are price-takers. They prove that, as the economy is infinitely replicated, the equilibrium outcome converges to the perfectly competitive one. Many authors pursue this line of research (Bonnisseau \& Florig, 2003; Busetto, Codognato, \& Ghosal, 2008; d’Aspremont, Ferreira, \& Varet, 1997; Gabszewicz \& Michel, 1997;

\footnotetext{
${ }^{1}$ It would have been preferable to isolate the effect of competition from the effect of diversification considering a multiproduct monopoly. But we prove in the appendix (Remark 1) that a monopolist having the possibility to produce two qualities would always choose to produce a single product.
} 
Lahmandi-Ayed, 2001). Unlike our model, in those papers differentiation is not considered and there is no decentralized social choice to make.

Another stream of literature exists on general equilibrium models with product differentiation (in the line of Cornet \& Medecin, 2006). But these papers consider only the question of existence and/or uniqueness of equilibrium with a general abstract modeling of differentiation not specific to a vertical one.

Our paper is situated at the crossroads of general equilibrium and vertical differentiation. To the best of our knowledge, the only paper which deals with vertical differentiation and labor in a general equilibrium framework is Lutz and Turrini (2006). Authors develop a model which links the labor endowments to the product quality. They consider two countries. In the first, there is an imperfectly competitive vertically differentiated product market where manufacturing higher quality needs higher labor skills. In the second, there is a perfectly competitive product market where a large number of firms produce a homogeneous good requiring unskilled labor. Consumers/workers in both countries are endowed with unskilled and skilled labor and are distributed according to their skill level. They have the choice to work in the differentiated sector or in the homogenous one and they also have the choice between consuming the high or low quality of the differentiated product, all residual income being spent in purchasing the homogenous good. Consumers/workers have different initial incomes and are also shareholders in the differentiated sector. Note that firms producing the differentiated product incur taxes on labor which are redistributed to consumers by the government. Our model differs from Lutz and Turrini (2006) in several respects. First, labor market is modeled differently; we consider that all consumers/workers have the same level of skills but differ by their sensitivity to effort (rather than a fixed qualification), choosing between the different options depending on that sensitivity and the level of wages. Second, as consumers, individuals in our model differ by their intensity of preference for quality whereas Lutz and Turrini (2006) consider individuals with identical preferences. Finally, whereas Lutz and Turrini (2006) focus on the analysis of the relation between some characteristics of the labor market (workers' skills, wages, and the tax rate) and the performance of a vertically differentiated product market under imperfect competition (in terms of imports and exports), our paper provides a theoretical approach concerning the outcome of a vote on the choice between monopoly and duopoly under two extreme ownership structures.

Our model may also be related to different strands of literature on collective choice. The main single winner voting systems referred to in the literature are (i) the simple majority voting systems (Miller, 1980) in which the winner is the candidate who receives more than all the other candidates combined; (ii) plurality voting systems (Denzau \& Kats, 1977; Dhillon \& Lockwood, 2004; Meir, Polukarov, Rosenschein, \& Jennings, 2010) where the candidate who receives the more votes wins; (iii) ordinal (or preferential) voting systems where voters rank the candidates according to their own preferences-in this category, we find the de Borda count (de Borda, 1781; Zahid \& de Swart, 2015), Bucklin voting (Erdelyi, Fellows, Rothe, \& Schend, 2015), or the Condorcet method (de Condorcet, 1785; Desmedt \& Elkind, 2010; Miller, 1980; Young, 1988); (iv) cardinal (or rated) voting systems that require the voter to give each candidate a grade such as in range voting (Smith, 2000) and majority judgement (Balinski \& Laraki, 2011). All those approaches amount to the majority vote system when the choice is made between only two alternatives, as is the case in our model.

The remainder of the paper is organized as follows. Section 2 describes the basic model. Section 3 provides the equilibrium for the monopoly and the duopoly cases. In Sections 4 and 5, we analyze, respectively, the concentrated ownership and the egalitarian ownership cases. We conclude in Section 6. All proofs are given in the appendix.

\section{2 | THE BASIC MODEL}

Consider an economy with three goods: labor and a numéraire as inputs and an indivisible "differentiated" good as the unique output ("differentiated" in the sense that it may possibly be of different qualities perceived differently by consumers).

There is a population of workers/consumers/shareholders. Each individual is endowed with an indivisible unit of labor and a given quantity $e$ of the numéraire and is doubly characterized by a working parameter $\alpha \in[0, \bar{\alpha}]$ which captures the worker's sensitivity to effort, and a consumption parameter $\theta \in[0, \bar{\theta}]$, which measures the intensity of the 
consumer's preference for the product's quality. Individuals are assumed to be uniformly distributed over $[0, \bar{\alpha}] \times[0, \bar{\theta}]$, with a density normalized to 1.

Each worker/consumer $(\alpha, \theta)$ chooses sequentially, first to remain idle $(\bar{W})$ or to work in the differentiated sector and in which firm; second, to compose his/her consumption bundle, in particular to consume or not $(\bar{C})$ one unit of the differentiated product and from which firm.

We denote by $\lambda \geq 0$ the share of each individual in the firm's profit.

One or two firm(s) produce(s) differentiated product(s). One unit of the differentiated good requires one unit of labor. Labor is the only input and wages are endogenous since they balance supply and demand on the labor market (as will be explained later).

Individuals derive their utility from the consumption of these two goods as follows:

$$
V(x, t)=\theta q x+t
$$

where $x$ is the quantity of the differentiated product of quality $q$ and $t$ is the quantity of the numéraire.

The revenue of the individual stems from his/her initial endowment, labor, and dividends. If the individual chooses to work, he/she receives a wage but must incur a training cost $\alpha q$. Thus, the revenue stemming from working (to produce quality $q$ at wage $\omega$ ) is equal to $\omega-\alpha q$. If he/she chooses not to work, he/she receives no wage (and does not have to be trained), his/her revenue being limited to the initial endowment in the numéraire and to his/her share in the firm's profit.

We consider two extreme ownership structures: first, the concentrated ownership case where $\lambda=0$ for almost everybody; second, the egalitarian ownership case where $\lambda=\frac{1}{\overline{\bar{\theta}} \bar{\alpha}}$ for everybody.

\section{3 | THE EQUILIBRIUM}

In this section, we determine the equilibrium outcomes in two cases: monopoly and duopoly.

It is worth noting that the ownership structure (whether $\lambda=0$ or $\lambda \neq 0$ ) and therefore the income distribution (whether $\lambda \pi=0$ or $\lambda \pi \neq 0$ ) have effect neither on working/consumption choices nor on the equilibrium prices. This is true for monopoly as well as for duopoly.

\section{1 | Monopoly}

We consider one manufacturing firm which offers a product $q_{m}$ at price $p_{m}$. Each worker/consumer chooses first to work in the differentiated sector or not; second, he/she makes his/her consumption decision.

We begin by determining the working and consumption decisions of each individual depending on the individual's characteristics $(\alpha, \theta)$, the wage, the product's quality, and price (see Lemma A1 in the appendix). This is done comparing for each individual the indirect utilities resulting, respectively, from the working option and from idleness. The revenue in the working option encompasses the wage diminished by the required training cost, his/her shares in the firm's profit, and the initial endowment. The revenue in the idleness option is reduced to the two last components. For each working option, taking into account the corresponding revenue, we calculate the optimal consumption bundle by comparing between consuming one unit of the differentiated good and consuming only the numéraire good, and finally deduce the resulting indirect utility.

This gives rise to four types of individuals, depending on whether they consume $(C)$ or not $(\bar{C})$ and work $(W)$ or not $(\bar{W})$. Note that, due to the linearity of the utility function, the working decision is independent of the consumption decision. This allows us to calculate the product's demand and the supply of labor (see Lemma A2 in the appendix). The wage anticipated by the firm is the one which, given the output price it charges, balances supply and demand on the labor market. Proposition 1 provides the equilibrium outcome for monopoly. 
Proposition 1 (Monopoly equilibrium). At equilibrium, the monopoly chooses quality $q_{m}^{*}=\bar{q}$, price $p_{m}^{*}=\frac{\bar{\theta} \bar{q}(\bar{\theta}+2 \bar{\alpha})}{2(\bar{\theta}+\bar{\alpha})}$, and wage $\omega_{m}^{*}=\frac{\bar{\alpha} \bar{\theta} \bar{\theta}}{2(\bar{\theta}+\bar{\alpha})}$, making profit $\pi_{m}^{*}=\frac{\bar{\alpha} \bar{q} \bar{\theta}^{3}}{4(\bar{\theta}+\bar{\alpha})}$.

Obviously, at equilibrium, without competition and because there are no variable costs of quality provision, the monopoly is urged to choose the maximal quality possible.

\subsection{Duopoly}

Consider now two firms 1 and 2 producing two qualities $q_{1}$ and $q_{2}$ (with $q_{1}<q_{2}$ ), respectively, at prices $p_{1}$ and $p_{2}$.

Firms make their choices in a two step-game where they first choose qualities then prices, anticipating that wages $\omega_{1}$ and $\omega_{2}$ adjust to clear the labor market. The game is solved by backward induction.

Each worker/consumer chooses sequentially, first to remain idle $(\bar{W})$ or to work in the differentiated sector and in which firm $\left(W_{i}, i=1,2\right)$; second, their consumption bundle, in particular to consume or not $(\bar{C})$ one unit of the differentiated product and from which firm $\left(C_{i}, i=1,2\right)$. We begin by determining the working and consumption decisions of each individual, depending on the individual's characteristics $(\alpha, \theta)$, the wages, the products' qualities, and prices (see Lemma A3 in the appendix). There are nine types of individuals depending on whether they remain idle $(\bar{W})$ or work at Firm $1\left(W_{1}\right)$ or at Firm $2\left(W_{2}\right)$, and on whether they consume Firm 1's product $\left(C_{1}\right)$, consume Firm 2's product $\left(C_{2}\right)$, or consume nothing $(\bar{C})$. This yields the labor supplies and demands for Firms 1 and 2 (see Lemma A4 in the appendix).

Proposition 2 provides the equilibrium outcome for the duopoly.

Proposition 2 (Duopoly equilibrium). At duopoly equilibrium, Firm 1 chooses quality $q_{1}^{*}=\frac{4}{7} \bar{q}$, price $p_{1}^{*}=\frac{\bar{\theta} \bar{q}(\bar{\theta}+8 \bar{\alpha})}{14(\bar{\theta}+\bar{\alpha})}$, and wage $\omega_{1}^{*}=\frac{\bar{\alpha} \bar{\theta} \bar{q}}{2(\bar{\theta}+\bar{\alpha})}$, making profit $\pi_{1}^{*}=\frac{\bar{\alpha} \bar{q} \bar{\theta}^{3}}{48(\bar{\theta}+\bar{\alpha})} ;$

Firm 2 chooses quality $q_{2}^{*}=\bar{q}$, price $p_{2}^{*}=\frac{\bar{\theta} \bar{q}(\bar{\theta}+4 \bar{\alpha})}{4(\bar{\theta}+\bar{\alpha})}$, and wage $\omega_{2}^{*}=\frac{3 \bar{\alpha} \bar{\theta} \bar{q}}{4(\bar{\theta}+\bar{\alpha})}$, making profit $\pi_{2}^{*}=\frac{7 \bar{\alpha} \bar{q} \bar{\theta}^{3}}{48(\bar{\theta}+\bar{\alpha})}$.

Duopoly leads to the existence of more variety, through a low-cost variant that does not exist in monopoly. At equilibrium, firms differentiate their products and choose the same qualities as Choi and Shin (1992) who consider the same model with no production cost in a partial equilibrium setting. However, the potential for relevant comparison is limited by the existence in our model of labor market which results for instance in endogenous costs (wages) having no equivalent in Choi and Shin.

Corollary 1 provides interesting comparisons between monopoly and duopoly outcomes.

Corollary 1. Comparing the outcomes of equilibria obtained under monopoly (Proposition 1) and duopoly (Proposition 2), we have

$$
0<\frac{p_{1}^{*}}{q_{1}^{*}}<\frac{p_{2}^{*}-p_{1}^{*}}{q_{2}^{*}-q_{1}^{*}}<\frac{p_{m}^{*}}{q_{m}^{*}}<\bar{\theta}
$$

and

$$
0<\frac{\omega_{m}^{*}}{q_{m}^{*}}<\frac{\omega_{2}^{*}-\omega_{1}^{*}}{q_{2}^{*}-q_{1}^{*}}<\frac{\omega_{1}^{*}}{q_{1}^{*}}<\bar{\alpha} .
$$

First note that all the products' demands and labor supplies are proved to be positive (as they have been supposed to be).

As for products' demands, Corollary 1 implies that the monopoly's demand (between $\frac{p_{m}^{*}}{q_{m}^{*}}$ and $\bar{\theta}$ ) is smaller than Firm 2's demand alone (between $\frac{p_{2}^{*}-p_{1}^{*}}{q_{2}^{*}-q_{1}^{*}}$ and $\bar{\theta}$ ) under duopoly. Thus, the consuming population is larger under duopoly than under monopoly. This is because, under duopoly, there is on the one hand more variety, and on the other hand more competition, resulting in lower prices. 
As for labor, the number of workers under monopoly (between 0 and $\frac{\omega_{m}^{*}}{q_{m}^{*}}$ ) is smaller than the number of workers in Firm 2 alone under duopoly (between 0 and $\frac{\omega_{2}^{*}-\omega_{1}^{*}}{q_{2}^{*}-q_{1}^{*}}$ ). Thus there is a greater employment level under duopoly. Again under duopoly, a more varied offer of labor and higher wages, thanks to more competition on the labor market, lead to higher employment.

\section{4 | THE CONCENTRATED OWNERSHIP CASE}

In this case the proportion of individuals who are shareholders in the firm (monopoly case) or in both firms (duopoly case) is supposed to be negligible, which means that the individuals who own the firm(s) have a null density so that they do not weigh on the vote. To determine the outcome of the vote, we calculate and compare the indirect utilities of each individual under monopoly and duopoly at equilibrium. This will allow us to compare the number of individuals preferring one option to the number of individuals preferring the other one. Proposition 3 provides the majority vote outcome between duopoly and monopoly under concentrated ownership.

Proposition 3 (Vote outcome/Concentrated ownership case). In the concentrated ownership case, all individuals prefer duopoly to monopoly or are indifferent between both. Hence duopoly is chosen by the majority.

This means that duopoly Pareto-dominates monopoly in the concentrated ownership case. When ownership is concentrated (that is, $\lambda=0$ for almost every individual), individuals prefer duopoly to monopoly. Indeed, in this case, as almost no individual is a shareholder in the firms, the profits are of no interest in their satisfaction. As consumers, they prefer duopoly which pushes down prices relative to monopoly, thanks to more competition on the product market, and offers more variety. As workers, they also prefer duopoly as it offers more variety on the labor market and as competition on the labor market between two firms pushes up wages relative to the monopoly case.

This result is natural, given that this extreme case almost amounts to a partial equilibrium model where individuals are only workers/consumers, leading to standard results.

\section{5 | THE EGALITARIAN OWNERSHIP CASE}

Under egalitarian ownership regime, all individuals are supposed to hold an identical number $\lambda=\frac{1}{\bar{\alpha} \bar{\theta}}$ of shares in the firm(s). We again calculate and compare the indirect utilities of each individual under monopoly and duopoly integrating the profit share in the individuals' revenues. Proposition 4 provides the outcome of the majority vote resulting from the comparison.

Proposition 4 (Vote outcome/Egalitarian ownership case). In the egalitarian ownership case, denoting by $\delta=\frac{\bar{\theta}}{\bar{\alpha}}$, the majority votes for duopoly if and only if: $\delta>\delta_{1} ; \delta_{1} \simeq 0.629445$.

The comparison between the number of individuals preferring duopoly (SD) and the number of those preferring monopoly $(S M)$, is given in the $(\bar{\alpha}, \bar{\theta})$ space (Figure 1). From Proposition 4 and Figure 1, majority vote leads to duopoly when $\delta\left(=\frac{\bar{\theta}}{\bar{\alpha}}\right)$ is high enough. Otherwise vote leads to monopoly.

Recall that each individual is at the same time a shareholder, a consumer, and a worker. The shareholder is more interested in the monopoly option since the monopoly's profit is higher than the joint profit under duopoly. The worker is more interested in the duopoly option since competition on the labor market raises wages. Finally, the consumer is more interested in the duopoly option since competition on the product market softens prices and offers more variety. The choice of each individual results from a trade-off between these effects.

To understand Figure 1 , for a fixed value of $\bar{\alpha}$, an increase in $\bar{\theta}$ pushes up

- Prices under monopoly more than under duopoly. This is clear from the ranking of the derivative of equilibrium prices with respect to $\bar{\theta}: \frac{\partial p_{m}^{*}}{\partial \bar{\theta}}>\frac{\partial p_{2}^{*}}{\partial \bar{\theta}}>\frac{\partial p_{1}^{*}}{\partial \bar{\theta}}$. 


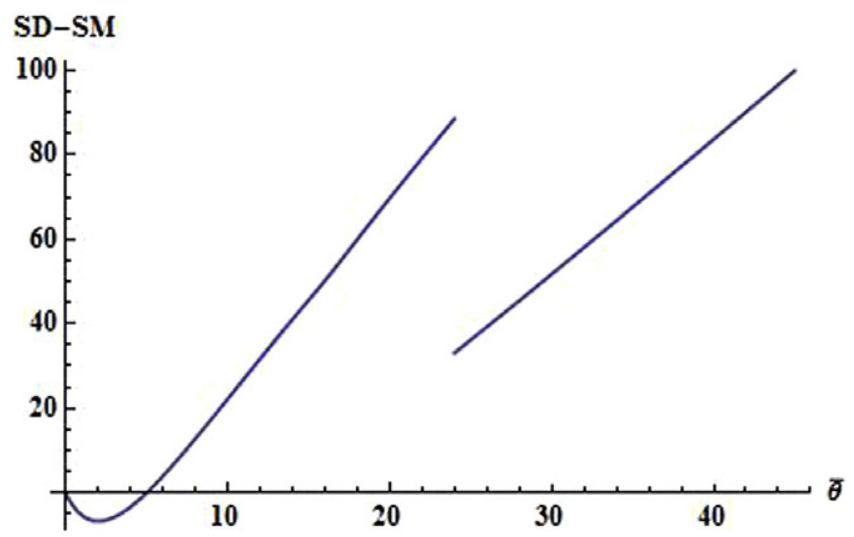

FIGURE 1 Vote outcome in the egalitarian ownership case.

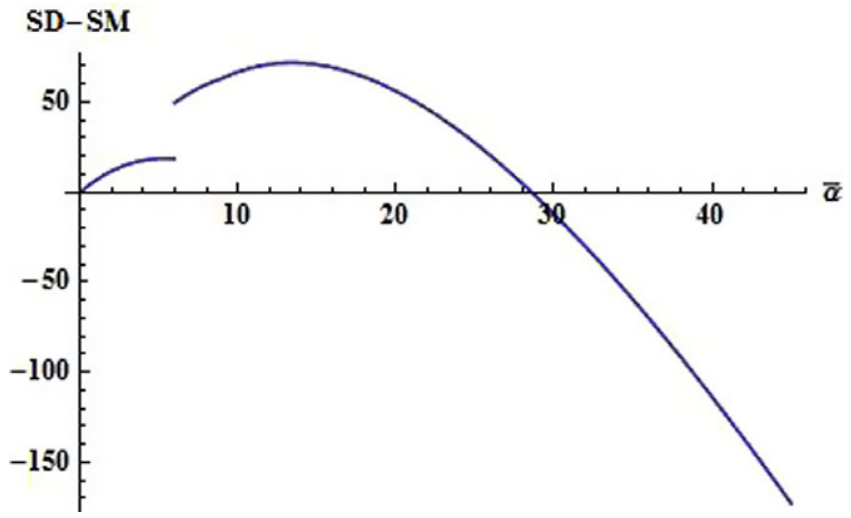

FIGURE $2 \quad \bar{\theta}$ Cross-section of SD $-S M: \bar{\theta}=18$.

- Wages under duopoly more than under monopoly. This can be seen also in the ranking of the derivative of wages with respect to $\bar{\theta}: \frac{\partial \omega_{m}^{*}}{\partial \bar{\theta}}=\frac{\partial \omega_{1}^{*}}{\partial \bar{\theta}}<\frac{\partial \omega_{2}^{*}}{\partial \bar{\theta}}$.

- Profits under monopoly more than under duopoly: $\frac{\partial \pi_{m}^{*}}{\partial \bar{\theta}}>\frac{\partial\left(\pi_{1}^{*}+\pi_{2}^{*}\right)}{\partial \bar{\theta}}$.

For high enough $\delta$, the worker and consumer effects outweigh the shareholder one.

The result we obtain may be seen from another viewpoint. Consider SD - SM (the difference between the number of individuals preferring duopoly and the number of individuals preferring monopoly) as a function of $\bar{\alpha}$ for a given $\bar{\theta}$ (Figure 2). Majority vote leads to duopoly when $\bar{\alpha}$ is low and to monopoly for high levels of $\bar{\alpha}$. Indeed, for low levels of $\bar{\alpha}$, the workers' segment is tight, which leads to harder competition between firms on the labor market and higher wages. The worker effect, together with the consumer effect which goes in the same direction, dominates the shareholder effect. A high level of $\bar{\alpha}$ releases competition on the labor market pushing down wages, allowing the shareholder effect to dominate the two other ones.

Consider now SD $-S M$ as a function of $\bar{\theta}$ for a given $\bar{\alpha}$ (Figure 3). Majority vote leads to monopoly for low values of $\bar{\theta}$ and to duopoly otherwise. Indeed, for low levels of $\bar{\theta}$, the consumers' segment is tight, which hardens competition on the product market, pushing down prices and profits under duopoly. The shareholder effect dominates the other effects, leading to preferring monopoly. A high level of $\bar{\theta}$ releases competition on the product market in the duopoly case, pushing up prices and profits under duopoly. In this case, the consumer and worker effects dominate the shareholder one, leading to preferring duopoly. 


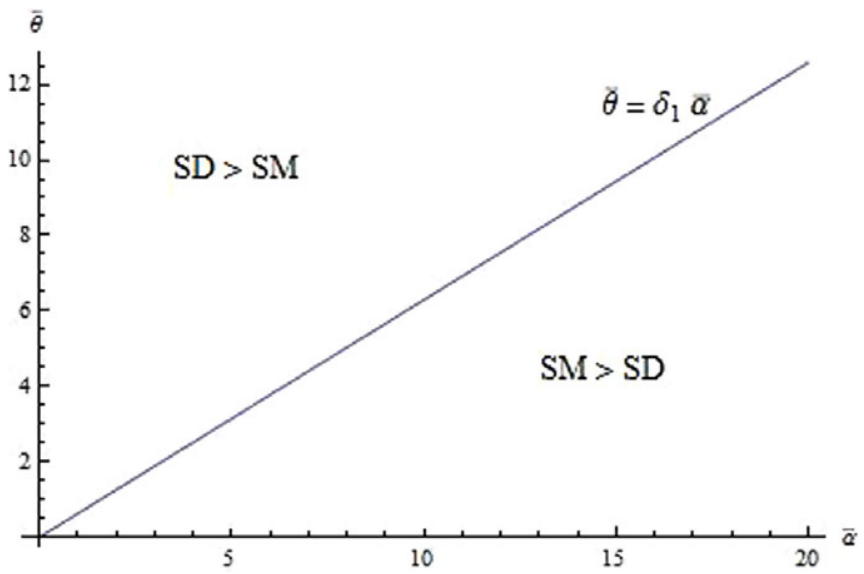

FIGURE $3 \quad \bar{\alpha}$ Cross-section of $S D-S M: \bar{\alpha}=8$.

\section{6 | CONCLUSION}

In this paper, we considered vertical differentiation within a general equilibrium model, where individuals are differentiated with respect to their preferences to quality and to their sensitivity to effort. We compared the monopoly and duopoly cases from the viewpoint of each individual, deducing the preference of the majority in two cases: concentrated and egalitarian ownership societies.

We prove that under concentrated ownership, duopoly is always preferred to monopoly. Under egalitarian ownership, the majority's choice depends on the relative size of the consumers' and workers' segments. We conclude that the outcome of a decentralized collective choice depends on the ownership structure and the characteristics of the markets at stake. More importantly, more competition is not necessarily desirable by the majority. More precisely, in the framework of our model, more competition is desirable regardless of the markets' characteristics, only when voters are excluded from ownership. Beyond the comparison between duopoly and monopoly, the proposed general equilibrium model allows us to deal with decentralized choice (through vote) between diverse options available to society, taking into account all the effects on the individuals. The proposed model should for instance allow us to deal with education issues, development economics issues, the production of public goods, among other questions of interest.

\section{REFERENCES}

Amir, R., Jin, J. Y., Pech, G., \& Tröge, M. (2016). Prices and deadweight loss in multiproduct monopoly. Journal of Public Economic Theory, 18, 346-362.

Anderson, S. P., de Palma, A., \& Thisse, J. F. (1992). Discrete choice theory of product differentiation. Cambridge, MA: MIT Press.

Bacchiega, E. (2007). Wage bargaining and vertical differentiation. International Review of Economics, 54, 35-52.

Balinski, M., \& Laraki, R. (2011). Election by majority judgment: Experimental evidence. In B. Grofman, A. Laurent, \& B. Dolez (Eds.), In situ and laboratory experiments on electoral law reform: French presidential elections (pp. 13-54). New York: Springer.

Bonnisseau, J. M., \& Florig, M. (2003). Existence and optimality of oligopoly equilibria in linear exchange economies. Economic Theory, 22, 727-741.

Busetto, F., Codognato, G., \& Ghosal, S. (2008). Cournot-Walras equilibrium as a subgame perfect equilibrium. International Journal of Game Theory, 37, 371-386.

Choi, C. J., \& Shin, H. S. (1992). A comment on a model of vertical product differentiation. Journal of Industrial Economics, 40, 229-231.

Cornet, B., \& Medecin, J. P. (2006). A general equilibrium model of spatial economies: The case of finite locations (Cahiers de la MSE). Paris: Université de Paris I. 
d'Aspremont, C., Ferreira, R. D. S., \& Varet, L. A. G. (1997). General equilibrium concepts under imperfect competition: A Cournotian approach. Journal of Economic Theory, 73, 199-230.

de Borda, J. C. (1781). Mémoire sur les élections au scrutin. Paris: Mémoires de l' Académie Royale des Sciences.

de Condorcet, M. (1785). Essai sur l'application de L'analyse à la probabilité des décisions rendues à la pluralité des voix. Paris: L' Imprimerie Royale.

Denzau, A. T., \& Kats, A. (1977). Expected plurality voting equilibrium and social choice functions. Review of Economic Studies, 44, 227-233.

Desmedt, Y., \& Elkind, E. (2010). Equilibria of plurality voting with abstentions. In D. C. Parkes \& M. Tennenholtz (Eds.), Proceedings of the 11th ACM conference on electronic commerce (pp. 347-356). New York: ACM Press.

Dhillon, A., \& Lockwood, B. (2004). When are plurality rule voting games dominance-solvable? Games and Economic Behavior, 46(1), 55-75.

Erdelyi, G., Fellows, M. R., Rothe, J., \& Schend, L. (2015). Control complexity in Bucklin and fallback voting: A theoretical analysis. Journal of Computer and System Sciences, 81, 632-660.

Gabszewicz, J. J., \& Michel, P. (1997). Oligopoly equilibria in exchange economies (CORE Discussion Papers, 1992047). Louvain, Belgium: Université catholique de Louvain, Center of Operations Research and Econometrics.

Gabszewicz, J., \& Turrini, A. (1999). Workers' skills and product selection. Revue économique, 50, 383-391.

Gabszewicz, J., \& Turrini, A. (2000). Workers' skills, product quality and industry equilibrium. International Journal of Industrial Organization, 18, 575-593.

Gabszewicz, J. J., \& Vial, J. P. (1972). Oligopoly à la Cournot in a general equilibrium analysis. Journal of Economic Theory, 4 , 381-400.

Hili, A., Lahmandi-Ayed, R., \& Lasram, H. (2015). Vertical differentiation and labor market: The differentiation principle revisited. Economics Bulletin, 35, 633-640.

Lahmandi-Ayed, R. (2001). Oligopoly equilibria in exchange economies: A limit theorem. Economic Theory, 17, $665-674$.

Li, C., \& Zhang, J. (2016). Program quality competition in broadcasting markets. Journal of Public Economic Theory, 18, 666-689.

Lutz, S., \& Turrini, A. (2006). A general equilibrium model with vertically differentiated industries, skilled labour and trade. Economic Modelling, 23, 1-19.

Meir, R., Polukarov, M., Rosenschein, J. S., \& Jennings, N. R. (2010). Convergence to equilibria in plurality voting. In Proceedings of the 24th AAAl conference on artificial intelligence, (pp. 823-828). Palo Alto, CA: AAI Press.

Miller, N. R. (1980). A new solution set for tournaments and majority voting: Further graph-theoretical approaches to the theory of voting. American Journal of Political Science, 24, 68-96.

Mussa, M., \& Rosen, S. (1978). Monopoly and product quality. Journal of Economic Theory, 18, 301-317.

Smith, W. D. (2000). Range voting (Technical Report 56). Princeton, NJ: NEC Research.

Wauthy, X. (1996). Quality choice in models of vertical differentiation. Journal of Industrial Economics, 44, 345-353.

Young, H. P. (1988). Condorcet's theory of voting. American Political Science Review, 82, 1231-1244.

Zahid, M. A., \& de Swart, H. (2015). The Borda majority count. Information Sciences, 295, 429-440.

\section{SUPPORTING INFORMATION}

Additional Supporting Information may be found online in the supporting information tab for this article. 


\section{APPENDIX}

\section{Proofs}

We need Lemmas A1 and A2 in the proof of Proposition 1.

Lemma A1. Table A1 provides for each individual his/her consumption and working decisions and indirect utility, depending on his/her characteristics $(\alpha, \theta)$, the wage, the product's quality, and price.

Proof of Lemma A1. Consumption decision. Given his/her decision about work, each individual makes his/her consumption choice to maximize his/her utility. Two cases are possible:

- If he/she has previously chosen $(\overline{\mathrm{W}})$, then he/she receives the revenue $R=\lambda \pi_{m}+e$.

If he/she consumes (C) one unit of product $a_{m}$, the budget constraint imposes $t=R-p_{m}$. The indirect utility obtained $U=\left(\theta q_{m}\right)+\left(R-p_{m}\right)=\left(\theta q_{m}\right)+\lambda \pi_{m}+e-p_{m} ;$

If he/she does not consume $(\bar{C})$ from the differentiated product, we have $t=R$ and the indirect utility $U=0+(R)=$ $\lambda \pi_{m}+e$.

Hence he/she decides to consume one unit of product $a_{m}$ when $\theta a_{m}>p_{m}$, otherwise, he/she does not purchase this product (he/she consumes only the numéraire).

- If he/she has previously chosen (W), his/her revenue is given by $R=\omega+\lambda \pi_{m}+e-\alpha q_{m}$.

If he/she consumes the differentiated product (C), he/she obtains the indirect utility $U=\left(\theta a_{m}\right)+\left(\omega_{m}+\lambda \pi_{m}+e-\right.$ $\left.\alpha q_{m}-p_{m}\right)$;

If he/she does not consume the differentiated product $(\bar{C})$, he/she obtains the indirect utility $U=0+\left(\omega_{m}+\lambda \pi_{m}+e-\right.$ $\left.\alpha q_{m}\right)$.

Again, he/she chooses $C$ if and only if $\theta q_{m}>p_{m}$.

A first conclusion is that the consumption decision is independent of the decision about working or not and of $\alpha$, this is due to the linearity of the utility function.

Decision of working. We have to consider two cases.

- When $\theta>\frac{p_{m}}{q_{m}}$, the individual consumes the differentiated product.

If he/she has previously chosen $W$, he/she will have the indirect utility $U=\left(\theta q_{m}\right)+\left(\omega_{m}+\lambda \pi_{m}+e-\alpha q_{m}-p_{m}\right)$;

If he/she has previously chosen $\bar{W}$, he/she will have the indirect utility $U=\left(\theta q_{m}\right)+\left(\lambda \pi_{m}+e-p_{m}\right)$.

The worker/consumer chooses $W$ if and only if $\omega_{m}>\alpha q_{m}$.

TABLE A 1 Consumption/working decisions and indirect utility $\left(U_{M}\right)$ of each individual in the monopoly case

\begin{tabular}{|c|c|c|c|}
\hline Consumption & W & $\frac{\omega_{m}}{q_{m}}$ & $\overline{\mathrm{W}}$ \\
\hline & $\mathrm{U}_{\mathrm{M}}=\omega_{\mathrm{m}}+\lambda \pi_{\mathrm{m}}+\mathrm{e}-\mathrm{aq}_{\mathrm{m}}$ & & $\mathrm{U}_{\mathrm{M}}=\lambda \pi_{\mathrm{m}}+\mathrm{e}$ \\
\hline C & $\mathrm{U}_{\mathrm{M}}=\theta \mathrm{q}_{\mathrm{m}}+\omega_{\mathrm{m}}+\lambda \pi_{\mathrm{m}}+\mathrm{e}-\mathrm{aq}_{\mathrm{m}}-\mathrm{p}_{\mathrm{m}}$ & & $\mathrm{U}_{\mathrm{M}}=\theta \mathrm{q}_{\mathrm{m}}+\lambda \pi_{\mathrm{m}}+\mathrm{e}-\mathrm{p}_{\mathrm{m}}$ \\
\hline
\end{tabular}


TAB LE A2 Consumption/working decisions and indirect utility $\left(U_{D}\right)$ of each individual in the duopoly case

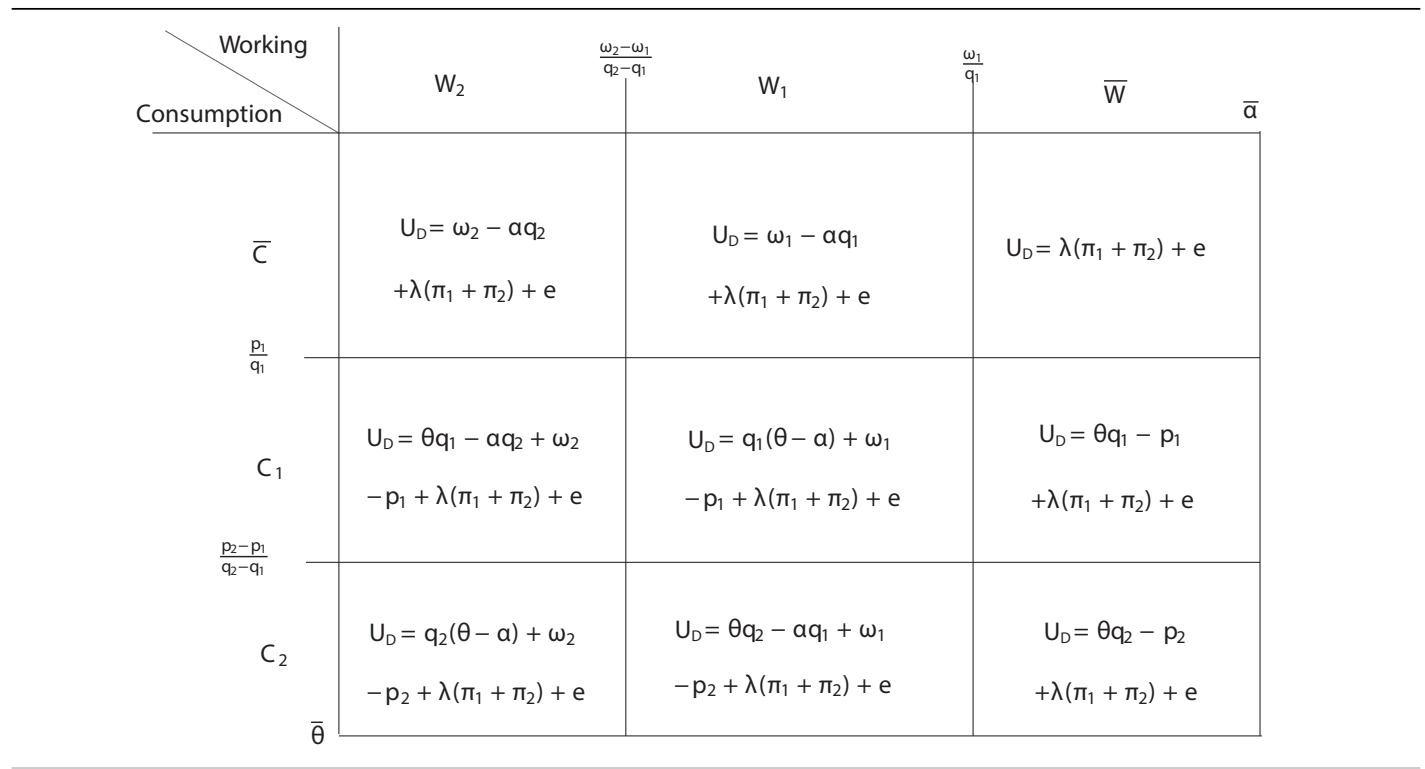

- When $\theta<\frac{p_{m}}{a_{m}}$, the individual does not consume the differentiated product.

If he/she has previously chosen $W$, he/she will obtain the indirect utility $U=0+\left(\omega_{m}+\lambda \pi_{m}+e-\alpha q_{m}\right)$.

If he/she has previously chosen $\bar{W}$, he/she will have the indirect utility $U=0+\left(\lambda \pi_{m}+e\right)$.

The worker/consumer chooses $W$ again if and only if $\omega_{m}>\alpha q_{m}$.

Lemma A2. Under monopoly, ${ }^{2}$ the labor supply in the differentiated sector is $\frac{\bar{\theta} \omega_{m}}{a_{m}}$. The demand for the differentiated product is $\bar{\alpha}\left(\bar{\theta}-\frac{p_{m}}{q_{m}}\right)$.

Proof of Lemma A2. Lemma A2 is easily derived from proof of Lemma A1.

Proof of Proposition 1. According to Lemma A2, the equilibrium on the labor market writes $\frac{\bar{\theta} \omega_{m}}{a_{m}}=\bar{\alpha}\left(\bar{\theta}-\frac{p_{m}}{q_{m}}\right)$, which provides the wage $\omega_{m}=\frac{\bar{\alpha}}{\bar{\theta}}\left(\bar{\theta} q_{m}-p_{m}\right)$. The profit is then given by $\pi_{m}=\bar{\alpha}\left(p_{m}\left(1+\frac{\bar{\alpha}}{\bar{\theta}}\right)-\bar{\alpha} q_{m}\right)\left(\bar{\theta}-\frac{p_{m}}{q_{m}}\right)$.

First order condition (F.O.C) with respect to $p_{m}$ leads to $p_{m}=\frac{\bar{\theta} a_{m}(\bar{\theta}+2 \bar{\alpha})}{2(\bar{\theta}+\bar{\alpha})}$, which yields the profit $\pi_{m}=\frac{\bar{\alpha} q_{m} \bar{\theta}^{3}}{4(\bar{\theta}+\bar{\alpha})}$.

The profit reaches its maximal value at $a_{m}^{*}=\bar{q}$. This yields $\omega_{m}^{*}=\frac{\bar{\alpha} \bar{\theta} \bar{\theta}}{2(\bar{\theta}+\bar{\alpha})}, p_{m}^{*}=\frac{\bar{\theta} \bar{q}(\bar{\theta}+2 \bar{\alpha})}{2(\bar{\theta}+\bar{\alpha})}, \pi_{m}^{*}=\frac{\bar{\alpha} \bar{q} \bar{\theta}^{3}}{4(\bar{\theta}+\bar{\alpha})}$, and the helpful values $\frac{p_{m}^{*}}{q_{m}^{*}}=\frac{\bar{\theta}(\bar{\theta}+2 \bar{\alpha})}{2(\bar{\theta}+\bar{\alpha})}, \frac{\omega_{m}^{*}}{q_{m}^{*}}=\frac{\bar{\alpha} \bar{\theta}}{2(\bar{\theta}+\bar{\alpha})}$.

We need Lemmas A3 and A4 in the proof of Proposition 2.

Lemma A3. In the duopoly case with $q_{1}<q_{2}$, Table A2 provides for each individual his/her consumption and working decisions and indirect utility, depending on his/her characteristics $(\alpha, \theta)$, on the wages, the products' qualities, and prices.

Proof of Lemma A3. We determine the indirect utility for each type of individuals in the same way as in proof of Lemma A1. The only difference is that in the duopoly case, each individual has the choice between consuming $q_{1}, q_{2}$ and not consuming; and working in Firm 1, in Firm 2, and remaining idle.

We notice that the consumption decision is independent of the working decision and of $\alpha$. Each individual decides to consume one unit of product $q_{2}$ when $\theta\left(q_{2}-q_{1}\right)>\left(p_{2}-p_{1}\right)$, and decides to consume one unit of product $q_{1}$ when $\theta q_{1}>p_{1}$ and $\theta\left(q_{2}-\right.$ $\left.q_{1}\right)<\left(p_{2}-p_{1}\right)$, otherwise he/she purchases neither product $a_{1}$ nor product $q_{2}$ (he/she consumes only the numéraire).

${ }^{2}$ We consider only interior solutions as we suppose positive product demand and labor supply for the firm. 
The decision of working is independent of $\theta$. Each individual chooses $W_{2}$ if and only if $\omega_{2}-\omega_{1}>\alpha\left(q_{2}-q_{1}\right)$, and chooses $W_{1}$ if and only if $\omega_{1}>\alpha q_{1}$ and $\omega_{2}-\omega_{1}<\alpha\left(q_{2}-q_{1}\right)$. Otherwise, he/she remains idle.

Lemma A4. Under Duopoly, ${ }^{3}$ the labor supplies for Firms 1 and 2 are, respectively, $\bar{\theta}\left(\frac{\omega_{1}}{q_{1}}-\frac{\omega_{2}-\omega_{1}}{q_{2}-q_{1}}\right)$ and $\bar{\theta}\left(\frac{\omega_{2}-\omega_{1}}{q_{2}-q_{1}}\right)$ and the demands for products of Firms 1 and 2 are, respectively, $\bar{\alpha}\left(\frac{p_{2}-p_{1}}{q_{2}-q_{1}}-\frac{p_{1}}{q_{1}}\right)$ and $\bar{\alpha}\left(\bar{\theta}-\frac{p_{2}-p_{1}}{q_{2}-q_{1}}\right)$.

Proof of Lemma A4. Lemma A4 is easily derived from the proof of Lemma A3.

Proof of Proposition 2. According to Lemma A4, equilibrium on the labor market writes

$\bar{\alpha}\left(\frac{p_{2}-p_{1}}{q_{2}-q_{1}}-\frac{p_{1}}{q_{1}}\right)=\bar{\theta}\left(\frac{\omega_{1}}{q_{1}}-\frac{\omega_{2}-\omega_{1}}{q_{2}-q_{1}}\right)$ and $\bar{\alpha}\left(\bar{\theta}-\frac{p_{2}-p_{1}}{q_{2}-q_{1}}\right)=\bar{\theta}\left(\frac{\omega_{2}-\omega_{1}}{q_{2}-q_{1}}\right)$, which yields $\omega_{1}=\bar{\alpha} q_{1}-\frac{\bar{\alpha}}{\bar{\theta}} p_{1}$ and $\omega_{2}=\bar{\alpha} q_{2}-\frac{\bar{\alpha}}{\bar{\theta}} p_{2}$. Inserting the obtained expressions in the firms' profits given by $\pi_{1}=\bar{\alpha}\left(p_{1}-\omega_{1}\right)\left(\frac{p_{2}-p_{1}}{q_{2}-q_{1}}-\frac{p_{1}}{q_{1}}\right)$ and $\pi_{2}=\bar{\alpha}\left(p_{2}-\omega_{2}\right)(\bar{\theta}-$ $\left.\frac{p_{2}-p_{1}}{q_{2}-q_{1}}\right)$, and writing F.O.C with respect to prices, yields the equilibrium prices $p_{1}=\frac{\bar{\theta} q_{1}\left(\bar{\theta}\left(q_{2}-q_{1}\right)+\bar{\alpha}\left(4 q_{2}-q_{1}\right)\right.}{(\bar{\theta}+\bar{\alpha})\left(4 q_{2}-q_{1}\right)}$ and $p_{2}=$ $\frac{\bar{\theta} q_{2}\left(2 \bar{\theta}\left(q_{2}-q_{1}\right)+\bar{\alpha}\left(4 q_{2}-q_{1}\right)\right.}{(\bar{\theta}+\bar{\alpha})\left(4 q_{2}-q_{1}\right)}$ and profits at price equilibrium $\pi_{1}=\frac{\bar{\alpha} q_{2} q_{1}\left(q_{2}-q_{1}\right) \bar{\theta}^{3}}{(\bar{\theta}+\bar{\alpha})\left(4 q_{2}-q_{1}\right)^{2}}, \pi_{2}=\frac{4 \bar{\alpha} q_{2}^{2}\left(q_{2}-q_{1}\right) \bar{\theta}^{3}}{(\bar{\theta}+\bar{\alpha})\left(4 q_{2}-q_{1}\right)^{2}}$.

The equilibrium in qualities is given by $q_{1}^{*}=\frac{4}{7} \bar{q}$ and $q_{2}^{*}=\bar{q}$.

At the subgame perfect equilibrium, the wages, prices, and profits are, respectively, given by

$$
\omega_{1}^{*}=\frac{\bar{\alpha} \bar{\theta} \bar{q}}{2(\bar{\theta}+\bar{\alpha})}, \omega_{2}^{*}=\frac{3 \bar{\alpha} \bar{\theta} \bar{q}}{4(\bar{\theta}+\bar{\alpha})} ; p_{1}^{*}=\frac{\bar{\theta} \bar{q}(\bar{\theta}+8 \bar{\alpha})}{14(\bar{\theta}+\bar{\alpha})}, p_{2}^{*}=\frac{\bar{\theta} \bar{q}(\bar{\theta}+4 \bar{\alpha})}{4(\bar{\theta}+\bar{\alpha})} ; \pi_{1}^{*}=\frac{\bar{\alpha} \bar{q} \bar{\theta}^{3}}{48(\bar{\theta}+\bar{\alpha})}, \pi_{2}^{*}=\frac{7 \bar{\alpha} \bar{q} \bar{\theta}^{3}}{48(\bar{\theta}+\bar{\alpha})} .
$$

Proof of Corollary 1. Simple calculations give

$\frac{p_{1}^{*}}{q_{1}^{*}}=\frac{\bar{\theta}(\bar{\theta}+8 \bar{\alpha})}{8(\bar{\theta}+\bar{\alpha})}, \frac{p_{2}^{*}-p_{1}^{*}}{q_{2}^{*}-q_{1}^{*}}=\frac{\bar{\theta}(12 \bar{\alpha}+5 \bar{\theta})}{12(\bar{\theta}+\bar{\alpha})}, \frac{\omega_{1}^{*}}{q_{1}^{*}}=\frac{7 \bar{\alpha} \bar{\theta}}{8(\bar{\theta}+\bar{\alpha})}$, and $\frac{\omega_{2}^{*}-\omega_{1}^{*}}{q_{2}^{*}-q_{1}^{*}}=\frac{7 \bar{\alpha} \bar{\theta}}{12(\bar{\theta}+\bar{\alpha})}$, which by simple comparison gives the announced inequalities.

Helpfully for the proofs of Propositions 3 and 4, Lemmas A1 and A3, together with Corollary 1, enable us to divide the set $([0, \bar{\alpha}] \times[0, \bar{\theta}])$ into 16 areas numbered from 1 to 16 , superimposing Tables $A 1$ and $A 2$. Then we assign to each area its corresponding monopoly and duopoly utilities, respectively, $U_{M}$ and $U_{D}$. To determine the majority vote, we have to compare $U_{D}$ and $U_{M}$ on each area. More details on these calculations are given in the online Supporting Information in "Details on the Proof of Proposition 3" and "Details on the Proof of Proposition 4."

Proof of Proposition 3. In the concentrated case, comparisons between $U_{M}$ and $U_{D}$ are summarized in Table A3. Clearly, we prove that all individuals prefer duopoly to monopoly or are indifferent between both.

Proof of Proposition 4. We first compare $U_{M}$ and $U_{D}$ under egalitarian ownership on each of the 16 areas identified above. Comparisons ${ }^{4}$ are summarized in Table A4. Second, for each area, we calculate the size of the subarea composed of the individuals preferring duopoly and of the one composed of the individuals preferring monopoly. Details of these calculations are given in the online Supporting Information. Finally, we sum up all the subareas preferring duopoly and denote the result by SD and sum up all the subareas preferring monopoly and denote the result by SM. Thus, SD and SM stand for the number of individuals preferring, respectively, duopoly and monopoly. We finally compute the difference $S_{D}-S_{M}$, which yields the following expression: ${ }^{5}$

$$
S D-S M= \begin{cases}\frac{\bar{\theta}\left(2784 \bar{\theta}^{2}+1476 \bar{\alpha} \bar{\theta}^{2}-133 \bar{\theta}^{3}-2304 \bar{\alpha}^{3}\right)}{2304(\bar{\theta}+\bar{\alpha})^{2}} & \text { if } 0<\bar{\theta} \leq 2 \bar{\alpha}, \\ \frac{\bar{\theta}\left(402 \bar{\alpha} \bar{\theta}^{2}+573 \bar{\theta}^{2}-19 \bar{\theta}^{3}-576 \bar{\alpha}^{3}\right)}{576(\bar{\theta}+\bar{\alpha})^{2}} & \text { if } 2 \bar{\alpha}<\bar{\theta}<3 \bar{\alpha}, \\ \frac{\bar{\theta} \bar{\alpha}\left(479 \bar{\theta}^{2}-\bar{\theta} \bar{\alpha}+49 \bar{\theta}-1152 \bar{\alpha}^{2}\right)}{1152(\bar{\theta}+\bar{\alpha})^{2}} & \text { if } 3 \bar{\alpha}<\bar{\theta} .\end{cases}
$$

\footnotetext{
${ }^{3}$ We consider only interior solutions as we suppose positive products' demands and labor supplies for all firms.

${ }^{4}$ When $\bar{\theta}=3 \bar{\alpha}$, all individuals of area 1 are indifferent between the two options. Hence, assigning the vote of these individuals to monopoly or duopoly is arbitrary and anyway does not affect the majority voting.

${ }^{5}$ It is worth noting that there is a discontinuity of $S D-S M$ at $\bar{\theta}=3 \bar{\alpha}$, due to the fact that on area 1 (Table A4), the difference $U_{M}-U_{D}$, which does not depend on the individuals' characteristics, is negative for every individual of the area when $\bar{\theta}<3 \bar{\alpha}$ and becomes positive for everybody when $\bar{\theta}>3 \bar{\alpha}$. For $\bar{\theta}=3 \bar{\alpha}$, all individuals of area 1 are indifferent between monopoly and duopoly. Their distribution between the two options, necessarily arbitrary, has no importance as it does not anyway change the majority vote (duopoly).
} 


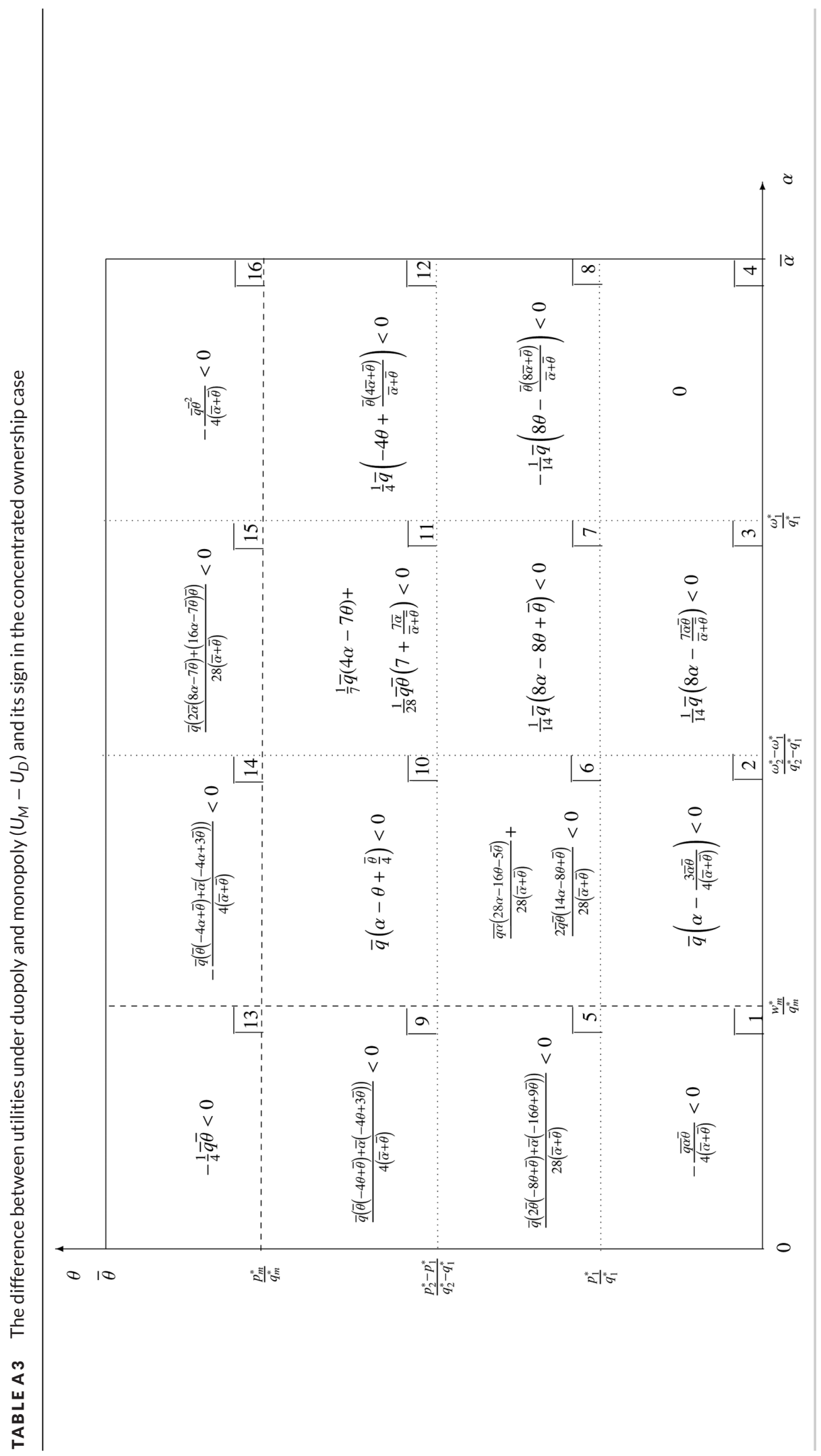




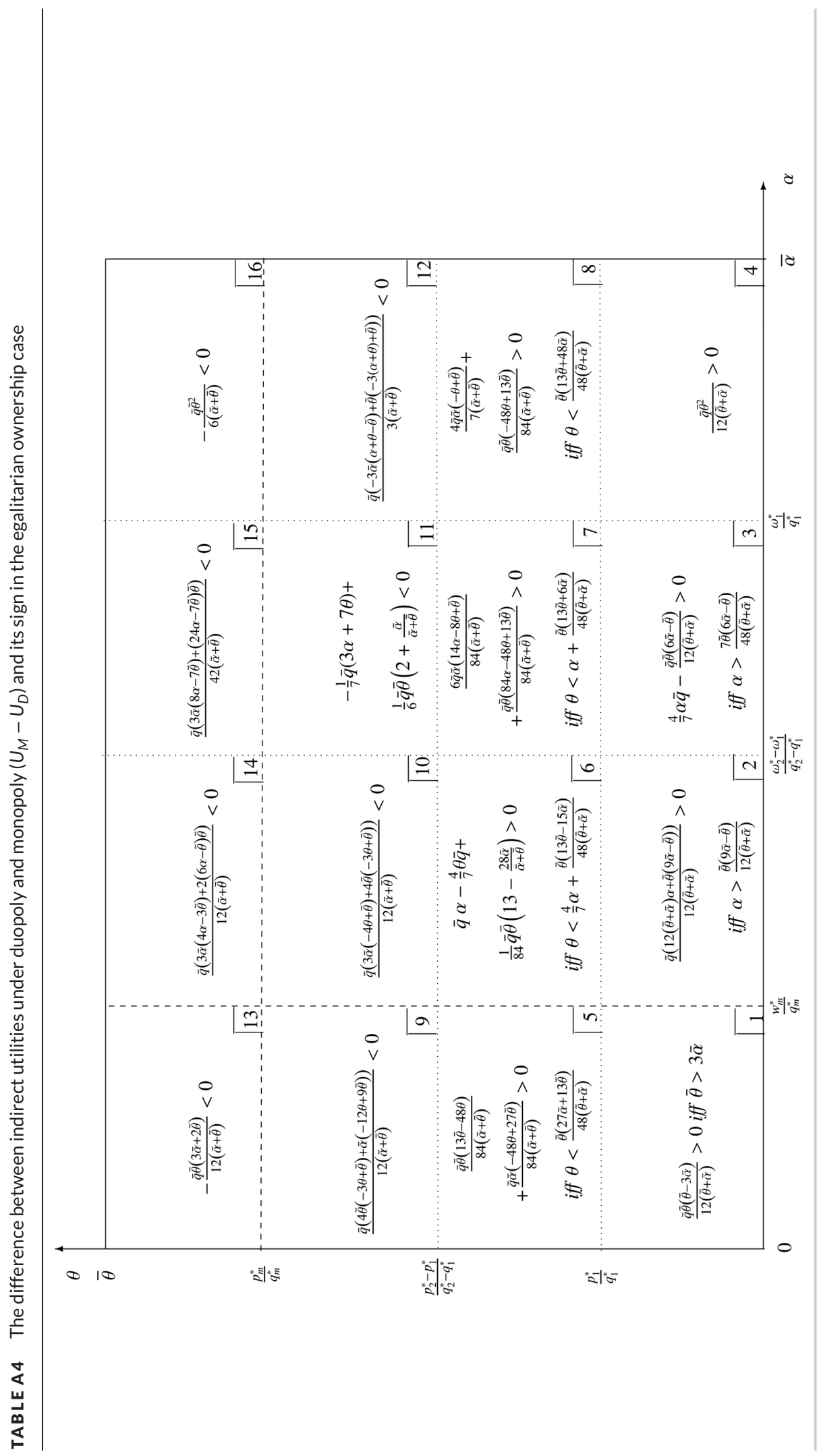


Note that SD - SM may be expressed as function of $\delta=\frac{\theta}{\bar{\alpha}}$.

- For $0<\bar{\theta} \leq 2 \bar{\alpha}$, equivalent to $0<\delta \leq 2$, SD - SM is of the same sign as $-133 \delta^{3}+1476 \delta^{2}+2784 \delta-2304$. We show that it is negative over the interval ]0,0.629445[ and positive over the interval ]0.629445,2].

- For $2 \bar{\alpha}<\bar{\theta}<3 \bar{\alpha}$, equivalent to $2<\delta<3$, SD - SM is of the same sign as $-19 \delta^{3}+402 \delta^{2}+573 \delta-573$. We show that it is positive over the interval ]2,3[.

- For $\bar{\theta}>3 \bar{\alpha}$, equivalent to $\delta>3, S D-S M$ is of the same sign as $479 \bar{\alpha} \delta^{2}+(49-\bar{\alpha}) \delta-1152 \bar{\alpha}$. We show that it is positive over the interval $] 3,+\infty[$.

Remark 1 (Multiproduct monopoly ). A monopolist having the possibility to produce two products will always choose to produce a single product.

Indeed, suppose that a monopolist produces two active qualities. This entails necessarily $0<\frac{p_{1}}{q_{1}}<\frac{p_{2}-p_{1}}{q_{2}-q_{1}}$. Necessary F.O.Cs imply $p_{1}^{*}=\frac{\bar{\theta} q_{1}(2 \bar{\alpha}+\bar{\theta})}{2(\bar{\theta}+\bar{\alpha})}$ and $p_{2}^{*}=\frac{\bar{\theta} q_{2}(2 \bar{\alpha}+\bar{\theta})}{2(\bar{\theta}+\bar{\alpha})}$. Thus, $\frac{p_{1}^{*}}{q_{1}}=\frac{p_{2}^{*}-p_{1}^{*}}{q_{2}-q_{1}}$, which is in contradiction with the initial assumption. 